\title{
Patient safety attitudes of pharmacy students in an Ethiopian university: a cross-sectional study
}

\section{Henok Getachew Tegegn \\ Tamrat Befekadu Abebe \\ Mohammed Biset Ayalew \\ Akshaya Srikanth \\ Bhagavathula}

Department of Clinical Pharmacy, School of Pharmacy, College of Medicine and Health Sciences, University of Gondar, Gondar, Ethiopia
Correspondence: Henok Getachew Tegegn

Department of Clinical Pharmacy, School of Pharmacy, College of Medicine and Health Sciences, University of Gondar, P.O. Box 196, Gondar, Ethiopia

Tel +25I $9 \mid$ I 438077

Fax +25। 058 II4 I 240

Email henok.getachew@uog.edu.et
This article was published in the following Dove Press journal:

Drug, Healthcare and Patient Safety

8 May 2017

Number of times this article has been viewed

Introduction: Patient safety is a major health care concern and is being included in an undergraduate curriculum as it plays a major role in lessening harm. Therefore, we aim to assess the attitude of pharmacy students toward patient safety.

Methods: A cross-sectional study using a self-administered questionnaire containing 21 items was conducted at the University of Gondar among fourth and fifth year students. Data analysis was performed to calculate mean, standard deviation, percentages, and logistic regressions using SPSS software version 22 (IBM Corporation, Armonk, NY, USA). Statistical significance was set at $P<0.05$.

Results: A total of 83 pharmacy students (fourth year groups $=50$, fifth year groups $=33$ ) participated in the study with response rate of $92 \%$. Majority of the students $70 / 83(84.33 \%)$ had the overall positive attitude of patient safety. Most of the respondents $(80.7 \%)$ agree or strongly agree that after an error occurs, an effective strategy is to work hard to be more careful. Most of them $(79.6 \%)$ believe that pharmacists should routinely spend part of their professional time working to improve patient care. About half (48.2\%) of pharmacy students disagree or strongly disagree that pharmacists should discuss and report errors to an affected patient and their family even if the patient is not harmed. No significant association between the attitude of pharmacy students toward patient safety and their age, sex and year of study was found.

Conclusion: Pharmacy students have the overall good attitude to patient safety. However, they claimed the culture and attitude within the pharmacy workplace lacked for patient safety. Moreover, standardized patient safety course should be considered in the curriculum for junior pharmacy students to improve their attitude toward patient safety.

Keywords: patient safety, culture, medication errors, patient care

\section{Introduction}

Patient safety has become the main concern of health care globally, particularly after the publication To Err is Human, ${ }^{1}$ and An Organisation with a Memory. ${ }^{2}$ The estimated numbers of patients harmed and high mortality due to medical errors have encouraged the establishment of evidence-based strategies to improve patient safety. ${ }^{3}$

A suitable education is suggested as the best strategy to improve attitude toward patient safety. ${ }^{4,5}$ Declaration of Helsinki endorsed the role of education: "Education plays a key role in improving patient safety and we entirely support the development, publishing and provision of patient safety education". ${ }^{6}$ The World Health Organization (WHO) has also introduced an inclusive patient safety curriculum. ${ }^{7}$

Most pharmacy degree programs, for example in Australia, currently embrace some elements of education from the WHO curriculum, such as medication safety, 
communication skills and patient-centered care. ${ }^{8}$ It is increasingly recognized that undergraduate (first degree) education plays a major role in the promotion of the proper notions, skills and knowledge about patient safety. ${ }^{9,10}$ As the Ethiopian Bachelor of Pharmacy (BPharm) curriculum has shifted from a 4-year product-oriented to a 5-year patient-oriented program, it necessitates the introduction of patient safety courses in the curriculum.

A number of survey tools have been applied to assess patient safety attitudes of health science and medical students. ${ }^{11-20}$ This study has used a 21-item patient safety tool validated by Walpola et $\mathrm{al}^{21}$ adapted from a survey developed by Madigosky et al. ${ }^{13}$ Preceding studies among pharmacy students have assessed patient safety knowledge and practice without using validated tools, ${ }^{11,12}$ and particularly, attitudes toward patient safety has remained unpublished. Therefore, the aim of this study is to evaluate patient safety attitudes of pharmacy students attending undergraduate program in University of Gondar.

\section{Material and methods}

\section{Study design, setting and participants}

A cross-sectional survey was conducted at the University of Gondar among fourth $(n=50)$ and fifth $(n=33)$ year undergraduate pharmacy students enrolled in the 5-year BPharm program in May 15, 2016. Verbal informed consent was obtained from the participants for their willingness to fill the questionnaires and included in the study.

We deemed that both fourth and fifth year groups are eligible to be enrolled in this study as patient safety education, including "pharmacy practice attachment" (hospital pharmacy, outpatient and inpatient ward practice), "drug informatics", and "communication skills for pharmacist" have been delivered in the curriculum for both groups prior to the study.

Data were collected between April 15 and 27, 2016. Participants' sociodemographic data and year of study were collected. We used a 21 -item patient safety tool validated by Walpola et al, ${ }^{21}$ which was adapted from the Patient Safety/ Medical Fallibility Curriculum Survey developed by Madigosky et al. ${ }^{13}$ Responses to each item were graded using a 4-point Likert scale (1=strongly disagree, $2=$ disagree, 3 =agree, $4=$ strongly agree).

\section{Ethical consideration}

The study was conducted after obtaining ethical clearance from the institutional review board of School of Pharmacy, UOG (University of Gondar). Before administering the questionnaire, the aim of the study was explained to the study participants and verbal informed consent was obtained. Furthermore, the data collected from each participant were kept confidential by gathering data anonymously using only their ID number and using data strictly for the purpose of the study only.

\section{Statistical analysis}

Data were analyzed using SPSS v22.0 (IBM Corporation, Armonk, NY, USA). Descriptive statistics was performed for sociodemographic data. Mean and standard deviation were computed for continuous variables, whereas frequency and percentages were computed for categorical variables. Association between the overall patient safety attitude of pharmacists and their sociodemographic characteristics was determined using Binomial logistic regression. Statistical significance was set at a two-sided $P<0.05$.

\section{Results}

A total of 83 out of 92 students ( $90.2 \%$ return rate) completed the questionnaires. All the students were in their fourth or fifth (last) year of study. Majority (63.9\%) were males. Most (94\%) of the participants were 21-24 years old. The mean age was $22.57 \pm 1.28$ years. Table 1 shows sociodemographic characteristics of study participants.

Most of the respondents (80.7\%) agree or strongly agree that after an error occurs, an effective strategy is to work hard to be more careful. They also believe peer-led education, such as from pharmacist colleagues or fellow students, can help their understanding of patient safety concepts. Majority ( $>80 \%$ ) of the study participants state that if they saw an error that did cause harm, they would not keep it to themselves. Most of them (79.6\%) believe that pharmacists should routinely spend part of their professional time working to improve patient care. About half (48.2\%) of the pharmacy

Table I Sociodemographic characteristics

\begin{tabular}{llll}
\hline Variables & Category & Frequency (n) & Percentage \\
\hline Sex & Male & 53 & 63.9 \\
& Female & 30 & 36.1 \\
Year of study & Fourth & 50 & 60.2 \\
& Fifth & 33 & 39.8 \\
Age & 21 & 17 & 20.5 \\
& 22 & 26 & 31.3 \\
& 23 & 23 & 27.7 \\
& 24 & 11 & 13.3 \\
& 25 & 2 & 2.4 \\
& 26 & 2 & 2.4 \\
& 27 & 1 & 1.2 \\
\hline
\end{tabular}


students disagree or strongly disagree on the discussing and reporting errors to an affected patient and their family even if the patient is not harmed. Table 2 shows the detailed description across all survey items of attitude of pharmacy students toward patient safety.

Multivariate logistic regression analysis showed no significant association between the attitude of pharmacy students toward patient safety and their age, sex and year of study (Table 3).

\section{Discussion}

Patient safety has become a significant issue for health care organizations striving to improve their service. Some patient safety investigations have indicated that organizations need

Table 2 The level of attitude of pharmacy students to patient safety

\begin{tabular}{|c|c|c|c|c|c|}
\hline SI. no & Items & $\begin{array}{l}\text { Strongly } \\
\text { disagree, } \mathbf{N}(\%)\end{array}$ & $\begin{array}{l}\text { Disagree, } \\
\text { N (\%) }\end{array}$ & Agree, N (\%) & $\begin{array}{l}\text { Strongly } \\
\text { agree, N (\%) }\end{array}$ \\
\hline I & $\begin{array}{l}\text { Competent health care professionals do not make errors } \\
\text { that lead to patient harm }\end{array}$ & 18 (21.7) & $31(37.3)$ & $21(25.3)$ & $13(15.7)$ \\
\hline 2 & $\begin{array}{l}\text { Pharmacists should routinely spend part of their } \\
\text { professional time working to improve patient care }\end{array}$ & $9(10.8)$ & $8(9.6)$ & $33(39.8)$ & $33(39.8)$ \\
\hline 3 & $\begin{array}{l}\text { Only medical practitioners can determine the causes of } \\
\text { a medical error }\end{array}$ & $29(34.9)$ & $29(34.9)$ & $13(15.7)$ & $12(14.5)$ \\
\hline 4 & $\begin{array}{l}\text { The culture of the pharmacy workplace makes it easy for } \\
\text { pharmacy staff to deal constructively with errors }\end{array}$ & $14(16.9)$ & $24(28.9)$ & $25(30.1)$ & $20(24.1)$ \\
\hline 5 & $\begin{array}{l}\text { Learning how to improve patient safety is an appropriate } \\
\text { use of time in pharmacy programs at university }\end{array}$ & $12(14.5)$ & $26(31.3)$ & $24(28.9)$ & $21(25.3)$ \\
\hline 6 & $\begin{array}{l}\text { Health care professionals, including pharmacy staff, } \\
\text { routinely share information about errors and what } \\
\text { caused them }\end{array}$ & $12(14.5)$ & $20(24.1)$ & $31(37.3)$ & $20(24.1)$ \\
\hline 7 & $\begin{array}{l}\text { In my experience, faculty and staff communicate to me } \\
\text { that patient safety is a high priority }\end{array}$ & I4 (I6.9) & $16(19.3)$ & 31 (37.3) & $22(26.5)$ \\
\hline 8 & $\begin{array}{l}\text { Pharmacists should report errors to an affected patient } \\
\text { and their family if harm to the patient has occurred }\end{array}$ & $16(19.3)$ & $20(24.1)$ & $29(34.9)$ & $18(21.7)$ \\
\hline 9 & $\begin{array}{l}\text { Pharmacists should discuss and report errors to an } \\
\text { affected patient and their family even if the patient is } \\
\text { NOT harmed }\end{array}$ & $10(12.0)$ & $30(36.1)$ & $27(32.5)$ & $16(19.3)$ \\
\hline 10 & $\begin{array}{l}\text { Effective responses to errors in the delivery of health } \\
\text { care focus primarily on the health care professional } \\
\text { involved }\end{array}$ & $6(7.2)$ & I8 (21.7) & $38(45.8)$ & $21(25.3)$ \\
\hline II & $\begin{array}{l}\text { Disciplinary action against an individual who made an } \\
\text { error is an effective method of preventing future errors }\end{array}$ & $7(8.4)$ & $17(20.5)$ & $31(37.3)$ & $28(33.7)$ \\
\hline 12 & $\begin{array}{l}\text { If there is no harm to a patient, there is no need to } \\
\text { address an error }\end{array}$ & $27(32.5)$ & $22(26.5)$ & $22(26.5)$ & $12(14.5)$ \\
\hline 13 & $\begin{array}{l}\text { If I saw an error that DID cause harm, I would keep it } \\
\text { to myself }\end{array}$ & $42(50.6)$ & $26(31.3)$ & $7(8.4)$ & $8(9.6)$ \\
\hline 14 & $\begin{array}{l}\text { If I saw an error that DID NOT cause harm, I would } \\
\text { keep it to myself }\end{array}$ & $27(32.5)$ & $25(30.1)$ & $25(30.1)$ & $6(7.2)$ \\
\hline 15 & $\begin{array}{l}\text { Most errors are due to things that health care } \\
\text { professionals cannot do anything about }\end{array}$ & $21(25.3)$ & $37(44.6)$ & $14(16.9)$ & II (13.3) \\
\hline 16 & $\begin{array}{l}\text { After an error occurs, an effective strategy is to work } \\
\text { hard to be more careful }\end{array}$ & $7(8.4)$ & $9(10.8)$ & $41(49.4)$ & $26(31.3)$ \\
\hline 17 & $\begin{array}{l}\text { The care that we provide on a day-to-day basis could be } \\
\text { improved }\end{array}$ & $4(4.8)$ & $16(19.3)$ & $34(41.0)$ & $29(34.9)$ \\
\hline 18 & $\begin{array}{l}\text { It is acceptable for an intern pharmacist to question the } \\
\text { actions of a registered pharmacist }\end{array}$ & $7(8.4)$ & $14(16.9)$ & $39(47.0)$ & $23(27.7)$ \\
\hline 19 & $\begin{array}{l}\text { It is acceptable for a registered pharmacist to question } \\
\text { the decisions of a prescriber (such as a doctor or nurse } \\
\text { practitioner) }\end{array}$ & $7(8.4)$ & II (I3.3) & $31(37.3)$ & $34(41.0)$ \\
\hline 20 & $\begin{array}{l}\text { Patient safety education requires university lecturers to } \\
\text { teach patient safety concepts }\end{array}$ & $8(9.6)$ & 18 (21.7) & $30(36.1)$ & $27(32.5)$ \\
\hline 21 & $\begin{array}{l}\text { Peer-led education, such as from pharmacist colleagues } \\
\text { or fellow students, can help my understanding of patient } \\
\text { safety concepts }\end{array}$ & $2(2.4)$ & $14(16.9)$ & 31 (37.3) & $36(43.4)$ \\
\hline
\end{tabular}


Table 3 Association between attitudes of pharmacy students toward patient safety and their age, sex and year of study

\begin{tabular}{|c|c|c|c|c|c|}
\hline \multirow[t]{2}{*}{ Variables } & \multirow[t]{2}{*}{ Category } & \multicolumn{2}{|c|}{ Overall attitude } & \multirow[t]{2}{*}{ COR $(95 \% \mathrm{Cl})$} & \multirow[t]{2}{*}{ AOR $(95 \% \mathrm{Cl})$} \\
\hline & & Negative (\%) & Positive (\%) & & \\
\hline \multirow[t]{2}{*}{ Sex } & Male & $9(17.0)$ & $44(83.0)$ & $0.752(0.210-2.688)$ & $0.852(0.217-3.344)$ \\
\hline & Female & $4(13.3)$ & $26(86.7)$ & 1.00 & 1.00 \\
\hline \multirow[t]{2}{*}{ Year of study } & Fourth & $8(16.0)$ & $42(84.0)$ & $1.067(0.316-3.596)$ & $1.330(0.303-5.834)$ \\
\hline & Fifth & $5(I 5.2)$ & $28(84.8)$ & 1.00 & 1.00 \\
\hline \multirow[t]{7}{*}{ Age (years) } & 21 & $3(17.6)$ & $14(82.4)^{-}$ & & \\
\hline & 22 & $2(7.7)$ & $24(92.3)$ & & \\
\hline & 23 & $4(17.4)$ & $19(82.6)$ & & \\
\hline & 24 & $3(27.3)$ & $8(72.7)$ & $0.872(0.558-1.36 \mathrm{I})$ & $0.839(0.474-1.484)$ \\
\hline & 25 & I (50.0) & I (50.0) & & \\
\hline & 26 & $0(0.0)$ & $2(100)$ & & \\
\hline & 27 & $0(0.0)$ & I $(100)$ & & \\
\hline
\end{tabular}

Abbreviations: $\mathrm{AOR}$, adjusted odds ratio; $\mathrm{COR}$, crude odds ratio; $\mathrm{Cl}$, confidence interval.

to change their culture to make it "easy to do the right thing, and hard to do the wrong thing" for patient care. ${ }^{22}$ Majority of studies conducted throughout the world regarding perceptions related to patient safety assessed the attitude of medical students and to our knowledge, there is no study done on perception of pharmacy students about patient safety. So, this study will highlight on the attitude of pharmacy students toward patient safety.

Majority of the students (59\%) did not agree with the view that competent health care professionals do not make errors that lead to patient harm. In contrast to this finding, studies conducted in Iran, Pakistan and China reported lower level of disagreement over this issue $(19.4 \%, 33.6 \%$ and $46 \%$, respectively). ${ }^{23,24,14}$ However, in the current study the presence of more than one-third (41\%) students who believe competent health care professionals do not make errors, indicate a fundamental misconception about the nature and pattern of human error. ${ }^{25}$

Around one-third of study participants (30.1\%) believe that most errors are due to things that health care professionals cannot do anything about. This is in close agreement with the result of the study conducted on students of Urmia University (Iran), which reported $32.3 \%$ of students think that most errors are due to things that physicians cannot do anything about. ${ }^{23}$ In contrast to our finding, very low level of agreement over this item is reported in the study done by Leung GK and Patil NG, which showed only 3\% of medical students perceive that most errors are due to things that health care professionals cannot do anything about. ${ }^{14}$

Reporting medical errors is an important step in improving the quality of health care, including patient safety. ${ }^{26}$ It was encouraging to see that majority of our students supported reporting of medical errors, indicated by more than half $(56.6 \%)$ of the students agreeing or strongly agreeing that pharmacists should report errors to an affected patient and their family if harm to the patient has occurred. Most of the students reported that they would not keep an error to themselves if they saw it. Similar to this finding, $73.9 \%$ of medical students of Dow Medical College reported that if they saw a medical error, they would not keep it to themselves. ${ }^{24}$ However, in the current study, some students (37.3\%) expressed that they would keep it to themselves if the error did not cause harm. The significant number of students who did not see the need to address a "no harm" error reflects a lack of awareness of "near miss" events and their potential impact on service improvement. ${ }^{27}$

One of the common misconceptions seen in about $30 \%$ of the students was that only medical practitioners can determine the causes of medical error. In line with our findings, other studies conducted on medical students also reported that $15 \%$ and $27.4 \%$ of students agree that only physicians can determine the causes of a medical error. ${ }^{14,23}$ We believe that in addition to the people involved, all professionals, managers and patients should also participate in the discussion about an error occurred in the patient care practice. This is an opportunity to share experiences between different professionals to clarify how the error happened and how it could be prevented, because it may not be the result of an isolated act of a professional. ${ }^{28}$

As for prevention, most students $(80.7 \%)$ believe that after an error occurs, an effective strategy is to work hard to be more careful. This was also the belief of majority of students (88\%) according to the report of a study done in China. ${ }^{14}$ However, evidence shows that assuming errors can be avoided by being careful enough and working hard can be dangerous, as human infallibility is inevitable and a major 
contributing factor toward adverse events. ${ }^{29}$ In addition to this, a significant number of errors may occur due to reasons other than carelessness of pharmacists.

Most (79.6\%) of pharmacy students believe that pharmacists should routinely spend part of their professional time working to improve patient care. Similarly, studies conducted in China and Pakistan reported that $85 \%$ and $89.4 \%$ of medical students believe that physicians should routinely spend part of their professional time working to improve patient care by giving due attention to not committing an error. ${ }^{24,14}$ Studies comparing students before and after the introduction of formal patient safety information in curricula have demonstrated an improvement in knowledge, skills and awareness. ${ }^{13,15}$ Majority of participants in this study also believe that patient safety education requires university lecturers to teach patient safety concepts. So it is recommended to include patient safety issues in the curriculum either as a separate subject or as part of a related course.

Many students had negative perception toward their practice work environment in relation to assuring patient safety. This was indicated by disagreement of $45.8 \%$ of students with the item stating "the culture of the pharmacy workplace makes it easy for Pharmacy staff to deal constructively with errors". This is a relatively more negative perception regarding the culture of work environment compared with what was reported in the Pakistan study. ${ }^{24}$

In the current study, age, sex and years of study have no significant relation with students' attitudes to patient safety. In the same manner, Mozafari et al reported the factors such as age, gender and years of work experience did not contribute toward the overall perception among emergency medicine residents. ${ }^{30}$ In contrast to our finding, a study done in Iran reported the presence of significant relationships between students' attitudes to patient safety with years of study and sex. ${ }^{23}$ The study done in Saudi Arabia also reported female doctors had a more positive attitude toward patient safety than male doctors. ${ }^{26}$

The strength of the present study was the use of a validated survey instrument and a sample of students from the 2 groups of pharmacy students who had exposure to pharmacy practice activities. The result of the study may not be generalized to health science students in the country since it is a single-centered study conducted solely on pharmacy students of Gondar University. As attitude is highly influenced by culture, the result of the study may not be generalized to pharmacy students who are outside Ethiopia. The use of self-administered questionnaires may allow respondents to over- or under-report attitude. We are confident that responses were self-reported in an anonymous and confidential setting but, given the nature of surveyed topic, we may not exclude possibility overinflated responses.

\section{Conclusion}

Pharmacy students in University of Gondar have good attitude with some misconceptions regarding patient safety. However, they claimed a good culture of the pharmacy workplace is lacking for patient safety. No sociodemographic characteristics were associated with the attitude of pharmacy students toward patient safety. The roles of all health care providers need to be acknowledged to lessen medical errors and patient harm. Moreover, standardized patient safety course should be considered in junior pharmacy students in the curriculum.

\section{Acknowledgments}

The authors thank all the pharmacy students who participated in this study.

\section{Author contributions}

HGT contributed to the conception, designing and conducting the study, and drafting the manuscript. TBA analyzed and interpreted the data. MBA was involved in supervision and writing the manuscript. ASB was involved in designing the study, drafting the manuscript, and its critical review. All authors contributed toward data analysis, drafting and revising the paper and agree to be accountable for all aspects of the work.

\section{Disclosure}

The authors report no conflicts of interest in this work.

\section{References}

1. Kohn LT, Corrigan J, Donaldson MS. To Err is Human: Building a Safer Health System. Washington, DC: Institute of Medicine; 2000.

2. Department of Health. An Organisation with a Memory. London, UK: Department of Health; 2000.

3. Frush KS. Fundamentals of a patient safety program. Pediatr Radiol. 2008;38(Suppl 4):S685-689.

4. Carruthers S, Lawton R, Sandars J, Howe A, Perry M. Attitudes to patient safety amongst medical students and tutors: developing a reliable and valid measure. Med Teach. 2009;31(8):e370

5. Hindle D, Braithwaite J, Iedema R. The Centre for Clinical Governance Research, Patient Safety Research: A review of the technical literature. Sydney: University of New South Wales; 2005

6. Rall M, van Gessel E, Staender S. Education, teaching \& training in patient safety. Best Prac Res Clin Anaesthesiol. 2011;25(2):251-262.

7. Walton M, Woodward H, Van Staalduinen S, et al. The WHO patient safety curriculum guide for medical schools. Qual Saf Health Care. 2010;19(6):542-546.

8. Marriott JL, Nation RL, Roller L, et al. Pharmacy education in the context of Australian practice. Am J Pharm Educ. 2008;72(6):126.

9. Flanagan B, Nestel D, Joseph M. Making patient safety the focus: crisis resource management in the undergraduate curriculum. Med Educ. 2004;38(1):56-66. 
10. Fischer MA, Mazor KM, Baril J, Alper E, DeMarco D, Pugnaire M. Learning from mistakes. Factors that influence how students and residents learn from medical errors. J Gen Intern Med. 2006;21(5):419-423.

11. Kiersma ME, Darbishire PL, Plake KS, Oswald C, Walters BM. Laboratory session to improve first-year pharmacy students' knowledge and confidence concerning the prevention of medication errors. Am JPharm Educ. 2009;73(6):99.

12. Sukkari SR, Sasich LD, Tuttle DA, Abu-Baker AM, Howell H. Development and evaluation of a required patient safety course. Am J Pharm Educ. 2008;72(3):65.

13. Madigosky WS, Headrick LA, Nelson K, Cox KR, Anderson T. Changing and sustaining medical students' knowledge, skills, and attitudes about patient safety and medical fallibility. Acad Med. 2006;81(1):94-101.

14. Leung GK, Patil NG. Patient safety in the undergraduate curriculum: medical students' perception. Hong Kong Med J. 2010;16(2):101-105.

15. Halbach JL, Sullivan LL. Teaching medical students about medical errors and patient safety: evaluation of a required curriculum. Acad Med. 2005;80(6):600-606.

16. Schnall R, Stone P, Currie L, Desjardins K, John RM, Bakken S. Development of a self-report instrument to measure patient safety attitudes, skills, and knowledge. J Nurs Scholarsh. 2008;40(4):391-394.

17. Flin R, Patey R, Jackson J, Mearns K, Dissanayaka U. Year 1 medical undergraduates' knowledge of and attitudes to medical error. Med Educ. 2009;43(12):1147-55.

18. Dudas RA, Bundy DG, Miller MR, Barone M. Can teaching medical students to investigate medication errors change their attitudes towards patient safety? BMJ Qual Saf. 2011;20(4):319-325.

19. Moskowitz E, Veloski JJ, Fields SK, Nash DB. Development and evaluation of a 1-day interclerkship program for medical students on medical errors and patient safety. Am J Med Qual. 2007;22(1):13-17.
20. Kiersma ME, Plake KS, Darbishire PL. Patient safety instruction in US health professions education. Am J Pharm Educ. 2011; 75(8):162.

21. Walpola RL, Fois RA, Carter SR, McLachlan AJ, Chen TF. Validation of a survey tool to assess the patient safety attitudes of pharmacy students. BMJ Open. 2015;5(9):e008442.

22. WHO. Human Factors in Patient Safety: Review of Topics and Tools. Geneva, Switzerland: World Health Organization; 2009.

23. Nabilou B, Feizi A, Seyedin H. Patient safety in medical education: students' perceptions, knowledge and attitudes. PLoS One 2015; 10(8):e0135610.

24. Shah N, Jawaid M, Shah N, Ali S. Patient safety: perceptions of medical students of Dow Medical College, Karachi. J Pak Med Assoc. 2015;65(12):1261-1265.

25. Norris B. Human factors and safe patient care. J Nurs Manag. 2009; 17(2):203-211.

26. Al-Khaldi YM. Attitude of primary care physicians toward patient safety in Aseer region, Saudi Arabia. J Fam Community Med. 2013; 20(3):153-158

27. Wakefield A, Attree M, Braidman I, Carlisle C, Johnson M, Cooke H. Patient safety: do nursing and medical curricula address this theme? Nurse Educ Today. 2005;25(4):333-340.

28. Yoshikawa JM, de Sousa BE, Peterlini MA, et al. Comprehension of undergraduate students in nursing and medicine on patient safety. Acta Paul Enferm. 2013;26(1):21-29.

29. WHO. Patient Safety Curriculum Guide. Multi-professional Edition. Available from: URL:http://whqlibdoc.who.int/publications/ 2011/9789241501958_eng.pdf.

30. Mozafari J, Fahimi M, Masoumi K, Darian A and Forouzan A. Emergency medicine residents perception about patient safety culture. Advan Biol Res. 2013;7(5):155-158.
Drug, Healthcare and Patient Safety

\section{Publish your work in this journal}

Drug, Healthcare and Patient Safety is an international, peer-reviewed open access journal exploring patient safety issues in the healthcare continuum from diagnostic and screening interventions through to treatment, drug therapy and surgery. The journal is characterized by the rapid reporting of reviews, original research, clinical, epidemiological and

\section{Dovepress}

post-marketing surveillance studies, risk management, health literacy and educational programs across all areas of healthcare delivery. The manuscript management system is completely online and includes a very quick and fair peer-review system. Visit http://www.dovepress.com testimonials.php to read real quotes from published authors. 